Sharif University of Technology
Scientia Iranica
SCIENTIA
IRAN ICAA

\title{
A new model for predicting liquid holdup in two-phase flow under high gas and liquid velocities
}

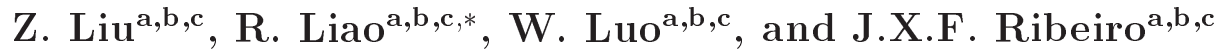 \\ a. Petroleum Engineering College, Yangtze University, 430100, Wuhan Campus, No. 111, Caidian Street, Caidian District, Hubei \\ Province, China. \\ b. The Multiphase Flow Laboratory of Gas Lift Innovation Centre, CNPC, 430100, Wuhan Campus, No. 111, Caidian Street, \\ Caidian District, Hubei Province, China. \\ c. The Branch of Key Laboratory of CNPC for Oil and Gas Production, Yangtze University, Jingzhou 434023, China.
}

Received 18 December 2017; received in revised form 30 July 2018; accepted 15 October 2018

\author{
KEYWORDS \\ Gas-liquid two-phase \\ flow; \\ Annular flow; \\ Higher gas and liquid \\ velocities; \\ Low liquid holdup.
}

\begin{abstract}
Existing liquid holdup models are generally based on low gas and liquid velocities. To extend the applicable range of existing liquid holdup prediction models and improve their prediction accuracy, a gas-liquid two-phase flow experiment was carried out using a pipe with an inner diameter of $60 \mathrm{~mm}$ and a length of $11.5 \mathrm{~m}$. The superficial gas and liquid velocity ranges were $14.07 \sim 56.50 \mathrm{~m} / \mathrm{s}$ and $0.205 \sim 1.426 \mathrm{~m} / \mathrm{s}$, respectively. The results indicate that the liquid holdup decreases with an increase in the superficial gas velocity and increases with an increase in the superficial liquid velocity. A new annular flow model for calculating low liquid holdup in a horizontal pipe was developed and presented, considering the relationships between the friction factor ratio of the liquid phase and the gas-liquid interface as well as the superficial Reynolds number of the gas and liquid. The predictions of the model were found to be accurate with an average absolute error of $4.8 \%$. Further, by combining the approach of the Beggs-Brill model with that of the horizontal pipe model established in this paper, a new liquid holdup model that accounts for different angles was presented. It was observed that the resultant model was also accurate and had an average absolute error of $10 \%$.

(C) 2019 Sharif University of Technology. All rights reserved.
\end{abstract}

\section{Introduction}

Gas-liquid two-phase flow exists widely in petroleum, chemistry, nuclear power, aerospace, and other industries. In the petroleum industry, gas-liquid two-phase flow often occurs in oil and gas production wells and gathering pipelines, and its flow characteristics have significant influence on the production of reservoirs and the equipment on the ground. Liquid holdup is not only an important parameter for the classification of

\footnotetext{
*. Corresponding author. Tel.: +86 13507212378; Fax: +86 02769110039

E-mail address: liaoruiquan@263.net (R. Liao)
}

flow patterns, but also related to the calculation of the existing models of pressure drop.

Gas-liquid two-phase flow is more complicated than single-phase flow. Similarly, the determination of liquid holdup is also complex, because there are many factors that influence liquid holdup. Due to its complexity, most researchers have initially used empirical models to predict liquid holdup [1-3]. However, empirical models are based on experiments and are applicable to experimental data in a certain range of conditions. It is difficult, therefore, to generalize and apply the empirical models to other experimental and operational conditions. With the development of gasliquid two-phase flow mechanisms and Computational Fluid Dynamics (CFD), several investigators have studied mechanistic models that can predict the liquid 
holdup and subsequent pressure drop for different angles [4-11]. One of the most significant mechanistic models, which is based on the dynamics of slug flow, was carried out by Zhang [8]. By using the entire film zone as the control volume, the momentum exchange between the slug body and the film zone was introduced into the momentum equations for slug flow.

Slug flow shares transition boundaries with all the other flow patterns. The equations of slug flow are used not only to calculate the slug characteristics but also to predict transitions from slug flow to other flow patterns. Slug liquid holdup is a critical slug flow characteristic for predicting average liquid holdup. Wang et al. [12] developed a complex mechanistic model for slug liquid holdup by using an empirical proportionality parameter generated from their data bank as a function of the Froude number and the inclination angle. Al-Safran [13] postulated several mechanisms of gas entrainment and evolution within the slug body and proposed a new simple empirical slug liquid holdup closure relationship valid for different liquid viscosities. Hassanlouei et al. [14] presented a methodology for calculating a slug liquid holdup in a horizontal pipe. The advantage of this method is that the slug unit holdup can be calculated directly based on the solutions of the flow field equations with no need to use correlations. Zuber and Findlay [15] first proposed the drift-flux model to predict the liquid holdup for slug flow, which has been well-researched and applied to gas-liquid two-phase pipe flows [16-21].

Some researchers used the two-fluid model to calculate liquid holdup of stratified and annular flow regimes [22-24]. The two-fluid model was developed by establishing and solving a momentum equation for each phase with corresponding closure relationships, which are often empirical in nature. Khaledi et al. [25] performed experiments with high density gas phase and oils of two different viscosities, and the obtained experimental results were compared with the predictions from a two-fluid gas-liquid model, which was presented by Unander et al. [26]. Dabirian et al. [27] studied the effects of phase velocities and fluid properties on the characteristics of stratified flow and proposed a closure relationship for the interfacial friction factor to predict the liquid holdup.

The mechanistic model is more accurate for liquid holdup prediction; however, it usually incorporates a system of nonlinear equations. In addition, the mechanistic model also relies on some assumptions and empirical constants obtained by experiments. Due to the limitation of such experimental conditions, the superficial gas and liquid velocities for most gas-liquid two-phase flow experiments reported in the literature are generally not very high. Most of the experimental data for liquid holdup based on gas-liquid two-phase flow are derived from the Tulsa University Fluid Flow
Projects (TUFFP), where the superficial gas velocity range of the experimental loops in the laboratory is $0 \sim 44.8 \mathrm{~m} / \mathrm{s}$, while the superficial liquid velocity range is $0 \sim 1.83 \mathrm{~m} / \mathrm{s}$.

Therefore, it is necessary to develop a prediction model for liquid holdup and pressure drop based on experimental data and take advantage of different models. To obtain an accurate model for predicting liquid holdup at higher gas and superficial liquid velocities applicable to different angles, a two-phase flow experiment with higher gas and liquid velocities was carried out on a multi-phase flow experimental platform at Yangtze University where the superficial liquid velocity range was from 0.205 to $1.426 \mathrm{~m} / \mathrm{s}$, and the superficial gas velocity range was from 14.07 to $56.50 \mathrm{~m} / \mathrm{s}$. The flow patterns in the experiment were observed, and the influence of different factors on the liquid holdup under the experimental conditions was obtained by analyzing the experimental data. Finally, a new model for predicting low liquid holdup $\left(H_{L}<\right.$ 0.1 ) in horizontal pipes was presented. In addition, based on the Beggs-Brill model, a model for predicting the holdup at different angles was obtained under the condition of higher superficial gas and liquid velocities.

\section{Experimental facility and measurement methods}

\subsection{Experimental facility}

The experiment was carried out on the multi-phase flow experimental platform, which is the platform of the gas lift test base of CNPC located at the School of Petroleum Engineering, Yangtze University. The diagram of the experimental device is shown in Figure 1.

Liquid from the mixing tank is pressurized by a pump. After pressure stabilization and measurement, the liquid is mixed with measured compressed gas, and the mixed media are introduced together into the test section. The liquid returns to the mixing tank after separation from the gas as they pass through the gas-liquid separator. The inner diameter of the test section used in the experiment is $60 \mathrm{~mm}$. The length of the plexiglass pipe used to observe the flow pattern is $7 \mathrm{~m}$. The test section can be adjusted at an angle of $0 \sim 90^{\circ}$. Pressure, temperature, and pressure differential sensors, as well as quick closing valves and other devices, are installed on the pipe section. The distance between the two quickly closing valves is $9.5 \mathrm{~m}$, including the $7-\mathrm{m}$ Plexiglas tube and 2.5-m-long stainless steel tube. Control of the devices and extraction of data are done directly online at the control center. The test section is shown in Figure 2.

To ensure the reliability of the experimental data, high-precision instruments are used. The liquid flowmeters installed include Endress+Hauser/80E25 

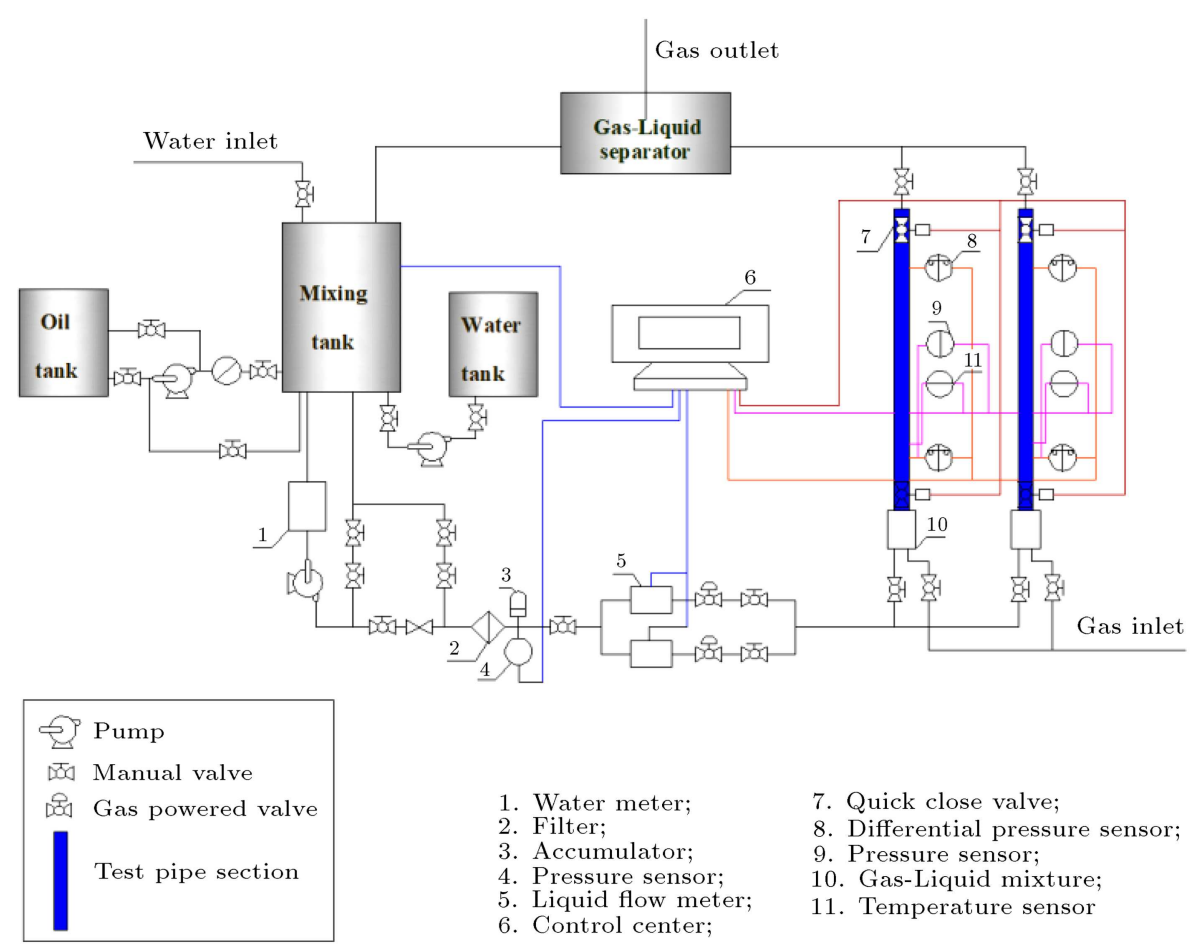

Figure 1. Multiphase flow test device.

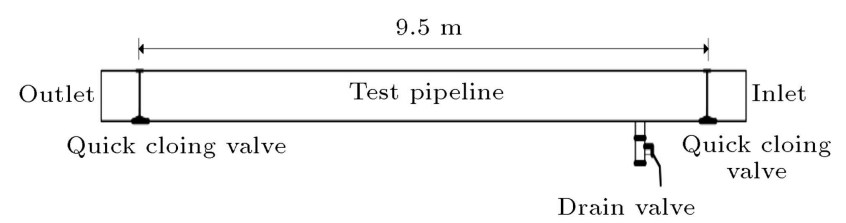

Figure 2. Liquid holdup test section.

and Endress+Hauser/80E50, while the gas flowmeter employed is Endress+Hauser $/ 65 \mathrm{~F} 1 \mathrm{H}$. All flowmeters measure the volume flow rate during the experiment. The response time of the quick-closing valve is $0.3 \sim$ $0.5 \mathrm{~s}$. The pressure and temperature sensors installed behind the quick-closing valve are used to measure the temperature and pressure in the test section. The measurement parameters and errors of each device are shown in Table 1.

Air is the gas phase, while water constitutes the liquid phase. The surface tension of the water is $0.071 \mathrm{Nm}^{-1}\left(23.58^{\circ} \mathrm{C}\right)$. The densities of water and air are $1000 \mathrm{~kg} / \mathrm{m}^{3}$ and $1.205 \mathrm{~kg} / \mathrm{m}^{3}$ (0.101 MPa), respectively, while their respective viscosities are 1 mPa.s and $0.0181 \mathrm{mPa} . \mathrm{s}\left(20^{\circ} \mathrm{C}\right)$.

\subsection{Experimental measurements}

Numerous researchers have reported various development lengths $(L / D$ ratios) for fully developed flow. Omebere et al. [28] demonstrated that $L / D=40$ was sufficient for a reasonably well-developed churnturbulent flow using probability density functions of the void fraction that showed the same shapes for this value and higher. In addition, some of the reported experimental observations are temporary or developing flow patterns, as described by Brennen [29]. Aliyu et al. [30] observed fully developed flow in a pipe position with $L / D=46$ for annular flow in upward vertical pipes. In the literature, no previous study provides conclusive experimental evidence or estimates of the minimum required length for the flow development section. This study provides approximately $2.4 \mathrm{~m}$ for the flow to develop, $L / D=40$, and our observations show that flow almost reaches development in this stage; therefore, the liquid holdup measurements could proceed.

In the experiment, a constant liquid flow rate was maintained, while the gas flow rate was adjusted.

Table 1. Measurement parameters and errors of the experimental devices.

\begin{tabular}{ccc}
\hline Equipment & Measuring range & Measurement error \\
\hline Pressure & $0 \sim 3.5 \mathrm{MPa}$ & $\pm 0.1 \%$ \\
Temperature & $0-90^{\circ} \mathrm{C}$ & $\pm 0.5 \%$ \\
Liquid flow rate & $2 \sim 20 \mathrm{~m}^{3} / \mathrm{h}$ & $\pm 0.3 \%$ \\
Gas flow rate & $160 \sim 2000 \mathrm{~m}^{3} / \mathrm{h}$ & $\pm 1 \%$ \\
\hline
\end{tabular}


Table 2. Range of parameters under the experimental conditions.

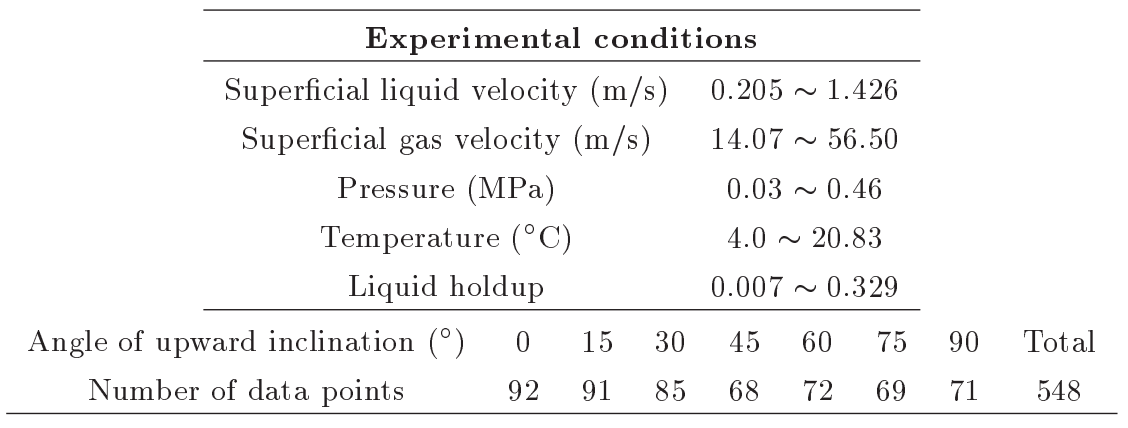

When the system was steady, the data were recorded, and the experimental flow pattern was observed. The experimental data were recorded every 5 seconds for 3 minutes; finally, the average value of each measurement parameter was obtained. After completing the data recording, the quick-closing valve was closed, and the liquid holdup was measured. The measurement method of liquid holdup was used to test the volume of residual liquid in the test section, and the ratio of the volume of the residual liquid to the volume of the whole pipe was used as the average liquid holdup of the experiment. The range of measurement parameters in the experiment is shown in Table 2.

\section{Experimental results and analysis}

\subsection{Experimental flow pattern}

Under the experimental conditions, the flow patterns observed in the horizontal pipe were slug and annular flow, attributed to the high superficial gas and liquid velocities. Experimental data points, indicating the observed flow patterns, plotted on the flow pattern maps presented by Mandhane et al. [31], Taitel and Dukler [32] and Zhang are shown in Figure 3. It can be observed that when the superficial gas velocity is approximately $12 \mathrm{~m} / \mathrm{s}$, the slug flow is transited to annular flow. With the increase of the superficial liquid velocity, the superficial gas velocity is required when the slug flow changing into annular flow increases gradually. It can also be observed that the experimental data fall near the transition boundary between slug flow and annular flow in the three flow pattern maps. It is found that the Mandhane flow pattern map is in excellent agreement with the experimental data.

In addition, slug flow, churn flow, and annular flow were observed in the inclined and vertical pipe sections. The experimental data points plotted on the flow pattern map of Kaya [33] for vertical pipes are presented in Figure 4. It can be seen from Figure 4 that the area of churn flow decreases with increasing superficial liquid velocity. It can also be observed that the flow pattern map of Kaya is consistent with the experimental data.

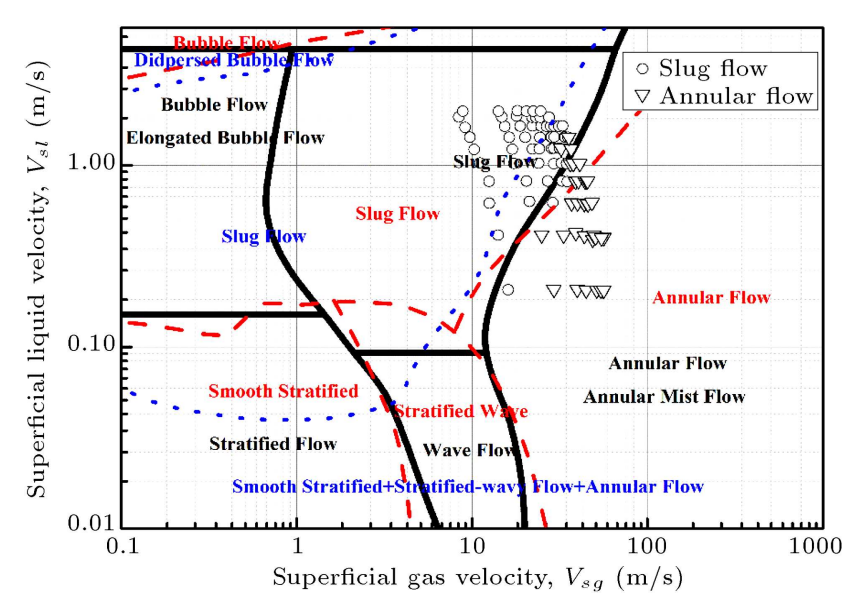

Figure 3. Test points on different horizontal flow pattern maps (black represents the Mandhane flow pattern map; blue color represents the Taitel-Dukler flow pattern map; and red represents the Zhang flow pattern map).

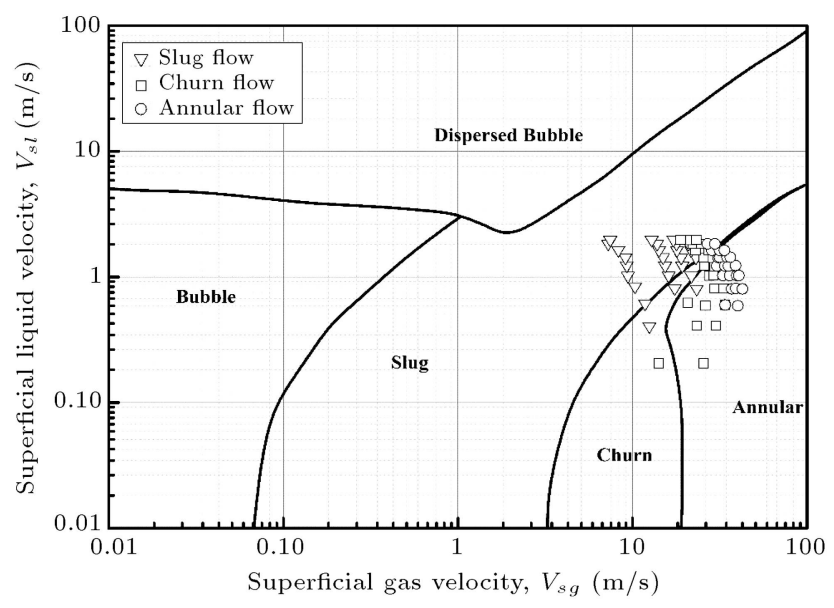

Figure 4. Test points on the Kaya flow pattern map.

\subsection{Liquid holdup versus superficial velocity and inclination}

The variation in liquid holdup with the superficial gas and liquid velocities is shown in Figure 5. From the horizontal to vertical orientation, the liquid holdup decreases with the increase of superficial gas velocity. When the superficial gas velocity is greater than 


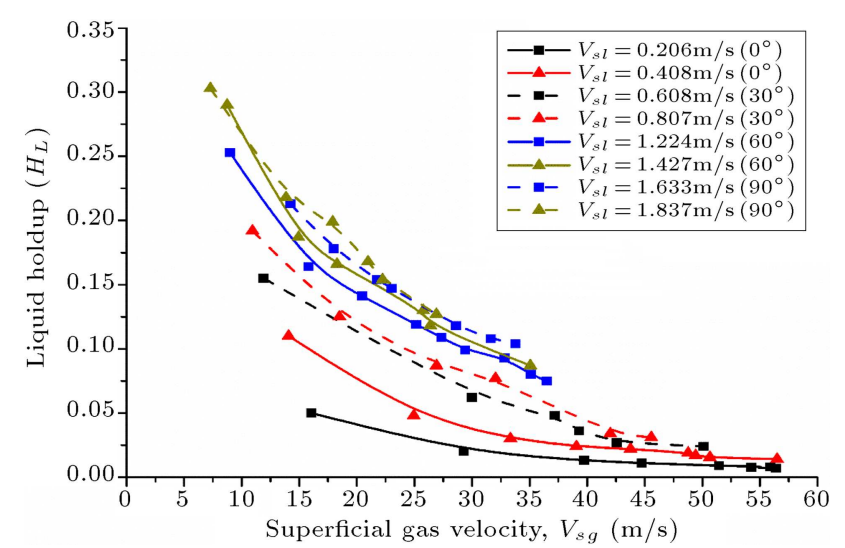

Figure 5. Liquid holdup versus superficial gas velocity with different inclinations (from horizontal to vertical).

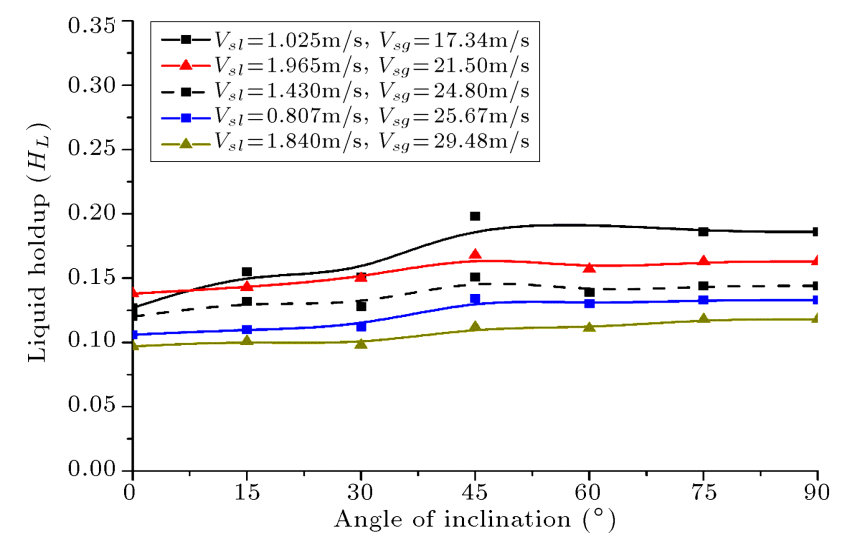

Figure 6. Liquid holdup versus angle of inclination.

$35 \mathrm{~m} / \mathrm{s}$, with an increase in superficial gas velocity, the liquid holdup decreases a little. When the superficial gas velocity is high enough, the flow pattern changes into annular flow, the liquid holdup is very low, and the influence of increasing gas velocity on liquid holdup is not obvious. The figure also shows that the liquid holdup increases with the increase of the superficial liquid velocity at the same superficial gas velocity.

The variation in liquid holdup with the inclination angle is shown in Figure 6. The liquid holdup increases

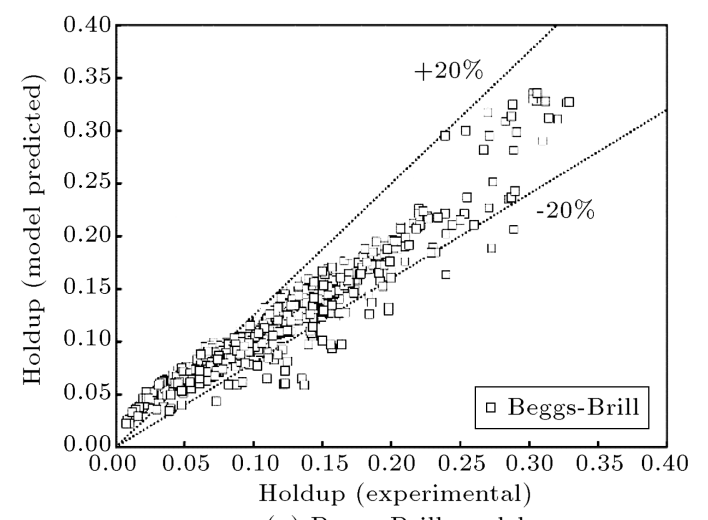

(a) Beggs-Brill model with the increase of the angle at the same superficial gas and liquid velocity and reaches the maximum value when the inclination angle is $45^{\circ}$. The liquid holdup decreases slightly; however, the change is small with the increase of the angle. This effect may result from the influence of gravity and viscosity, which can be seen in the literature study of Beggs [1]. When the inclination angle is less than $45^{\circ}$, the influence of angle on the liquid holdup decreases with the increase of the superficial gas velocity.

\subsection{Prediction of liquid holdup by empirical and mechanistic models}

The Beggs-Brill (B-B) empirical model and the Kaya mechanistic model were used to predict the experimental liquid holdup data. The Kaya model was applicable to deviated pipes and not suitable for horizontal pipes. Therefore, the Kaya model was used to predict the liquid holdup at the angle from $15^{\circ}$ to $90^{\circ}$, while the B-B model was used to predict the liquid holdup at the angle from $0^{\circ}$ to $90^{\circ}$. The results of the comparison between the predicted values of the two different models and the experimental data of the liquid holdup are shown in Figure 7. When the liquid holdup is low, the prediction of the liquid holdup from these two models is not accurate.

The prediction average relative error and the average absolute error are determined as follows:

Average relative error:

$$
E_{1}=\left(\frac{1}{n} \sum_{1}^{n} \frac{H_{L c a l}-H_{L \exp }}{H_{L \exp }}\right) \times 100 .
$$

Average absolute error:

$$
E_{2}=\left(\frac{1}{n} \sum_{1}^{n}\left|\frac{H_{L c a l}-H_{L \exp }}{H_{L \exp }}\right|\right) \times 100,
$$

where $H_{\text {Lcal }}$ is the liquid holdup predicted by the model, and $H_{\text {Lexp }}$ is the liquid holdup measured in the experiment.

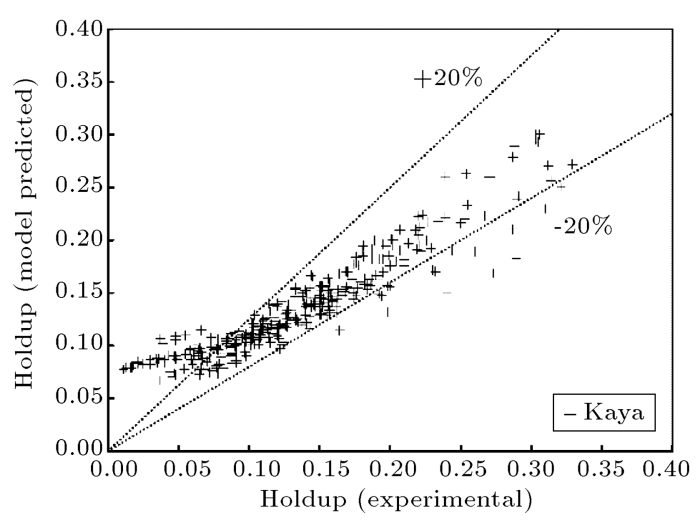

(b) Kaya model

Figure 7. Comparison of different models predicting liquid holdup with experimental data. 
Table 3. Errors of the B-B model and Kaya model.

\begin{tabular}{ccccccc}
\hline & \multicolumn{2}{c}{$\boldsymbol{H}_{\boldsymbol{L}}<\mathbf{0 . 1}$} & \multicolumn{2}{c}{$\boldsymbol{H}_{\boldsymbol{L}}>\mathbf{0 . 1}$} & \multicolumn{2}{c}{ All data } \\
\cline { 2 - 7 } Model & $\boldsymbol{E}_{\mathbf{1}}(\boldsymbol{\%})$ & $\boldsymbol{E}_{\mathbf{2}}(\boldsymbol{\%})$ & $\boldsymbol{E}_{\mathbf{1}}(\boldsymbol{\%})$ & $\boldsymbol{E}_{\mathbf{2}}(\boldsymbol{\%})$ & $\boldsymbol{E}_{\mathbf{1}}(\boldsymbol{\%})$ & $\boldsymbol{E}_{\mathbf{2}}(\boldsymbol{\%})$ \\
\hline B-B & 43.6 & 46.7 & -5.2 & 10.2 & 15.6 & 25.8 \\
Kaya & 66.4 & 67.1 & -3.9 & 8.9 & 19.7 & 28.5 \\
\hline
\end{tabular}

Table 4. The errors of B-B and Kaya models at different angles.

\begin{tabular}{ccccccccc}
\hline Model & Angle $\left({ }^{\circ}\right)$ & $\mathbf{0}$ & $\mathbf{1 5}$ & $\mathbf{3 0}$ & $\mathbf{4 5}$ & $\mathbf{6 0}$ & $\mathbf{7 0}$ & $\mathbf{9 0}$ \\
\hline \multirow{2}{*}{$\mathrm{B}-\mathrm{B}$} & $E_{1}(\%)$ & 38.5 & 35.2 & 33.2 & -4.0 & -0.8 & -5.5 & -4.5 \\
& $E_{2}(\%)$ & 41.9 & 41.7 & 40.1 & 11.6 & 13.4 & 10.0 & 8.7 \\
\multirow{3}{*}{ Kaya } & $E_{1}(\%)$ & - & 50.1 & 31.6 & 6.0 & 13.1 & 5.5 & 6.9 \\
& $E_{2}(\%)$ & - & 60.0 & 40.2 & 21.7 & 17.6 & 13.4 & 13.2 \\
\hline
\end{tabular}

The liquid holdup errors of $H_{L}<0.1$ and $H_{L}>$ 0.1 are shown in Table 3 . Accordingly, when $H_{L}<0.1$, the prediction values of the two models are greater than the experimental value. The average absolute error shows that the errors of the two models are high and more than $40 \%$. When $H_{L}>0.1$, the errors of the two models are lower, and the predicted values are lower than the experimental value. Based on the error of all the data, it can be seen that the errors of the two models are relatively high. However, the performance of the B-B model is better than that of the Kaya model; the errors of the B-B model are $15.6 \%$ and $25.8 \%$.

The errors of the two models at different angles are shown in Table 4. It can be observed that the errors of the two models decrease with the increase of the angle. The performance of the $\mathrm{B}-\mathrm{B}$ model is relatively better. When the angle is greater than $45^{\circ}$, the B-B model is more accurate and the error is approximately $10 \%$. However, the error is high; when the angle is less than $45^{\circ}$, all the errors are greater than $40 \%$.

\section{Model development and evaluation}

According to the error analysis, the error of the B$\mathrm{B}$ model is high when the liquid holdup is less than 0.1 . However, the liquid holdup prediction at different angles of the B-B model is based on the calculation of the liquid holdup of the horizontal pipe. Therefore, the development of a low liquid holdup correlation capable of predicting values less than 0.1 in the horizontal pipe is necessary. When the liquid holdup is low, the flow pattern of the horizontal pipe is either stratified or annular. However, no stratified flow was observed in this experiment. Therefore, the low liquid holdup $\left(H_{L}<0.1\right)$ model was developed based on annular flow.

Hart et al. [34] proposed the "Apparent Rough Surface" (ARS) model. Badie et al. [35] validated the two models by using the experimental data and attached the importance of liquid holdup prediction to the accuracy of pressure drop prediction. Meng et al. [22] added the concept of droplet entrainment on the basis of the "double-circle" model that was developed by Chen [36] and presented a new model. Fan [23] presented a two-fluid model that requires the initial value calculated by the ARS model proposed by Hart. $\mathrm{Xu}$ [24] combined the research results of Meng and Fan and presented a new model for calculating the low holdup and verifying it with the laboratory data from the experiments of Meng and Fan.

\subsection{Development of a liquid holdup model for the horizontal pipe}

The liquid phase in annular flow exists in two forms: a liquid film flowing along the pipe wall and the droplets entrained in the gas core. The shape of the liquid in annular flow is shown in Figure 8.
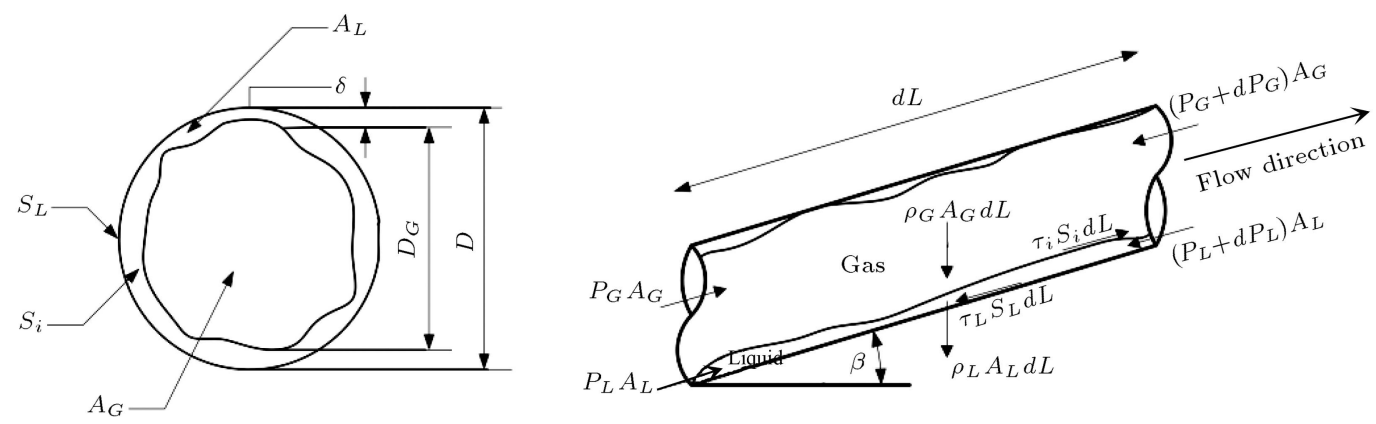

Figure 8. The morphology of gas-liquid two-phase flow in the pipe. 
The study follows the approach of Xiao [5], who presented an annular flow model with an average liquid film thickness around the pipe wall. The model was developed based on the momentum equation in the liquid film and the gas core.

Momentum equation of gas core:

$$
-A_{G}\left(\frac{d p}{d L}\right)_{G}-\tau_{i} S_{i}-\rho_{G} A_{G} g \sin \beta=0,
$$

where:

$\left(\frac{d p}{d L}\right)_{G} \quad \begin{aligned} & \text { The pressure gradient of the gas phase, } \\ & \mathrm{Pa} ;\end{aligned}$

$A_{G} \quad$ The cross-sectional area inside the pipe of the gas phase, $\mathrm{m}^{2}$;

$\tau_{i} \quad$ The shear stress of the interface, $\mathrm{N} / \mathrm{m}$;

$S_{i} \quad$ The perimeter of the interface, m;

$\rho_{G} \quad$ Density of the gas, $\mathrm{kg} / \mathrm{m}^{3}$;

$g \quad$ The gravity acceleration, $\mathrm{m} / \mathrm{s}^{2}$;

$\beta \quad$ The inclination angle, ${ }^{\circ}$.

The momentum equation of the liquid film:

$$
-A_{L}\left(\frac{d p}{d L}\right)_{L}-\tau_{L} S_{L}+\tau_{i} S_{i}-\rho_{L} A_{L} g \sin \beta=0,
$$

where:

$\left(\frac{d p}{d L}\right)_{L} \quad \begin{aligned} & \text { The pressure gradient of the liquid } \\ & \text { phase, } \mathrm{Pa} \text {; }\end{aligned}$

$A_{L} \quad$ The cross-sectional area inside the pipe of the liquid phase, $\mathrm{m}^{2}$;

$\tau_{L} \quad$ The shear stress of liquid film and wall, $\mathrm{N} / \mathrm{m}$;

$\rho_{L} \quad$ The density of the liquid, $\mathrm{kg} / \mathrm{m}^{3}$.

If the pressure drop gradient in the gas is equal to that in the liquid, Eqs. (3) and (4) can be combined to obtain the following combined momentum equation:

$$
\tau_{i} S_{i} A_{p}-\tau_{L} S_{L} A_{G}-A_{L} A_{G}\left(\rho_{L}-\rho_{G}\right) g \sin \beta=0
$$

where $A_{L}\left(\mathrm{~m}^{2}\right)$ is the cross-sectional area inside the pipe of the liquid phase.

The shear stresses are:

$$
\begin{aligned}
\tau_{L} & =f_{L} \frac{\rho_{L} v_{L}^{2}}{2}, \\
\tau_{i} & =f_{i} \frac{\rho_{G}\left(v_{G}-v_{i}\right)^{2}}{2},
\end{aligned}
$$

where:
$f_{L}, f_{i} \quad$ The liquid phase friction factor and the interfacial friction factor, $\mathrm{m}^{2}$;

$v_{L} \quad$ The average liquid velocity, $\mathrm{m} / \mathrm{s}$;

$v_{L} \quad$ The average gas velocity, $\mathrm{m} / \mathrm{s}$;

$v_{i} \quad$ The gas-liquid interface velocity, $\mathrm{m} / \mathrm{s}$.

The area of each phase can be expressed approximately as functions of pipe cross-sectional area and liquid holdup:

$$
\begin{aligned}
& A_{L}=A_{p} H_{L}, \\
& A_{G}=A_{p}\left(1-H_{L}\right),
\end{aligned}
$$

where $H_{L}$ is the liquid holdup.

Then, we can obtain that:

$$
\begin{gathered}
f_{L} \frac{\rho_{L} v_{L}^{2}}{2} S_{L} A_{p}\left(1-H_{L}\right)-f_{i} \frac{\rho_{G}\left(v_{G}-v_{L}\right)^{2}}{2} S_{i} A_{p} \\
+A_{p} H_{L} A_{p}\left(1-H_{L}\right)\left(\rho_{L}-\rho_{G}\right) g \sin \beta=0 .
\end{gathered}
$$

When the pipe is horizontal, Eq. (10) can be simplified as:

$$
\left(\frac{v_{L}}{v_{G}}\right)^{2}-\frac{1}{1-H_{L}} \frac{f_{i} \rho_{G} S_{i}}{f_{L} \rho_{L} S_{L}}\left(1-\frac{v_{L}}{v_{G}}\right)^{2}=0 .
$$

The average gas and liquid velocities are:

$$
\begin{aligned}
& v_{G}=\frac{v_{s g}}{1-H_{L}}, \\
& v_{L}=\frac{v_{s l}}{H_{L}},
\end{aligned}
$$

where $v_{s g}(\mathrm{~m} / \mathrm{s})$ is the superficial gas velocity, and $v_{s l}$ $(\mathrm{m} / \mathrm{s})$ is the superficial liquid velocity.

The gas-liquid interface velocity is difficult to obtain. Many researchers assume that the gas-liquid interface velocity equals the average liquid velocity, $v_{i} \approx v_{L}$

We define the parameter $a=\frac{H_{L}}{1-H_{L}}$, where $H_{L}=$ $\frac{a}{1+a}$. Eq. (11) can be transformed into:

$$
\left(\frac{v_{s l}}{v_{s g}}\right)^{2}-(1+a) \frac{f_{i} \rho_{G} S_{i}}{f_{L} \rho_{L} S_{L}}\left(a-\frac{v_{s l}}{v_{s g}}\right)^{2}=0 .
$$

According to the geometry of the flow pattern, the following equations can be obtained:

$$
\begin{aligned}
& S_{L}=\pi D, \\
& S_{i}=\pi(D-2 \delta),
\end{aligned}
$$

where $D(\mathrm{~m})$ is the internal diameter, and $\delta(\mathrm{m})$ is the liquid film thickness.

According to the assumption that the liquid film thickness on the wall of the annular flow is the same, 
the following relation between the liquid film thickness and the liquid holdup is given by Fan [23]:

$$
\delta=\frac{D\left(1-\sqrt{1-H_{L}}\right)}{2}
$$

By substituting Eq. (15) to (17) into Eq. (14), a can be calculated as follows (Eq. 18):

$$
a=\frac{v_{s l}}{v_{s g}}\left(\sqrt{\frac{f_{L} \rho_{L}}{f_{i} \rho_{G}}}\left(1-H_{L}\right)^{0.25}+1\right) .
$$

Finally, the implicit equations of liquid holdup are obtained as follows:

$$
H_{L}=\frac{v_{s l}}{v_{s g}}\left(\sqrt{\frac{f_{L} \rho_{L}}{f_{i} \rho_{G}}}\left(1-H_{L}\right)^{0.25}+1\right)\left(1-H_{L}\right) .
$$

Eq. (19) shows that the key to calculating the liquid holdup is to calculate the friction coefficient ratio between the liquid phase and the gas-liquid interface $\frac{f_{L}}{f_{i}}$. Hart et al. (1989) [34] reported the relationship between $\frac{f_{L}}{f_{i}}$ and the superficial liquid Reynolds number. According to the experimental results,

$$
\frac{f_{L}}{f_{i}}=108 \mathrm{R}_{e s l}-0.726
$$

According to the experimental data, $\frac{f_{L}}{f_{i}}$ can be calculated by Eq. (19); then, the corresponding superficial gas and liquid Reynolds number can also be calculated. The ratio of the friction coefficient between the liquid phase and the gas-liquid interface $\frac{f_{L}}{f_{i}}$ of different superficial gas and liquid Reynolds number is shown in Figure 9 . It can be seen from the figure that $\frac{f_{L}}{f_{i}}$ changes

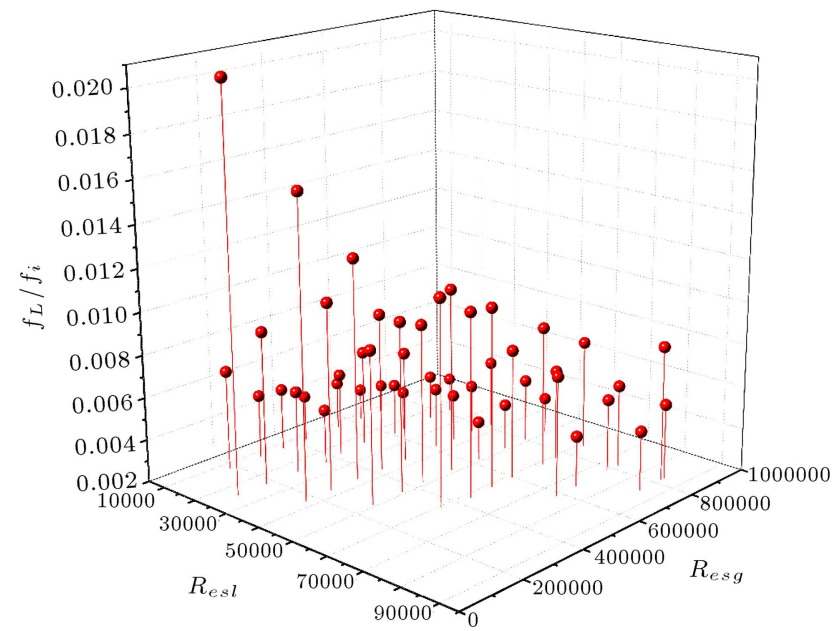

Figure 9. The ratio of friction coefficient between the liquid phase and the gas-liquid interface $\left(\frac{f_{L}}{f_{i}}\right)$ versus superficial gas Reynold number $\left(R_{e s g}\right)$ and superficial liquid Reynold number $\left(R_{e s l}\right)$. not only with the superficial liquid Reynolds number, but also with the superficial gas Reynolds number.

Therefore, in the reference form of Eq. (20), the following equations are presented:

$$
\frac{f_{L}}{f_{i}}=x R_{e s l}^{y} R_{e s g}^{z}
$$

where:

$R_{e s l}=\frac{\rho_{L} v_{s l} D}{\mu_{L}}$ The superficial liquid Reynolds $R_{e s g}=\frac{\rho_{g} v_{s g} D}{\mu_{G}}$ The superficial gas Reynolds number; $\mu_{G} \quad$ The gas viscosity, mPa.s;

$\mu_{L} \quad$ The liquid viscosity, mPa.s.

By fitting the experimental data, the obtained parameters are as follows: $x=0.5756, y=0.5372$, and $z=-0.7734$.

\subsection{Evaluation of the new horizontal low liquid holdup model}

The calculation procedure for the new horizontal low liquid holdup model is as follows:

1. Select an initial value for the liquid holdup $\left(H_{L}=\right.$ $0.1)$;

2. Use Eq. (19) to calculate a new liquid holdup $H_{\text {Lnew }}$;

3. If $\left|H_{\text {Lnew }}-H_{L}\right|>0.0001$, then $H_{L}=H_{\text {Lnew }}$. Repeat step (2), until $\left|H_{\text {Lnew }}-H_{L}\right|<0.0001$.

There are 49 groups of data for which the liquid holdup is $H_{L}<0.1$ in the horizontal pipe. The results of a comparison between the predictions of 6 existing models (presented by B-B, M-B, Hart, Xiao, Chen, and Fan) and those of the present model and experimental data are shown in Figure 10. The figure shows that the B-B, Xiao, Fan, Chen and Hart models over-predict the experimental values. The average relative error and the average absolute error are all greater than $70 \%$. The performance of the M-B model is good, and the average relative error is $17.8 \%$. The average absolute error is $19.3 \%$; however, the error is relatively high. On the other hand, the present model gives better predictions than the existing models. The absolute error of the present model is within $20 \%$, the average absolute error is $4.8 \%$, and the average relative error is $0.62 \%$.

\subsection{Prediction and evaluation of the new liquid holdup model with different inclination angles at high velocity}

The presented model modifies the B-B model when the angle is less than $45^{\circ}$ and the liquid holdup is less than 0.1. The procedure for predicting the liquid holdup with the modified B-B model is presented in Figure 11. 


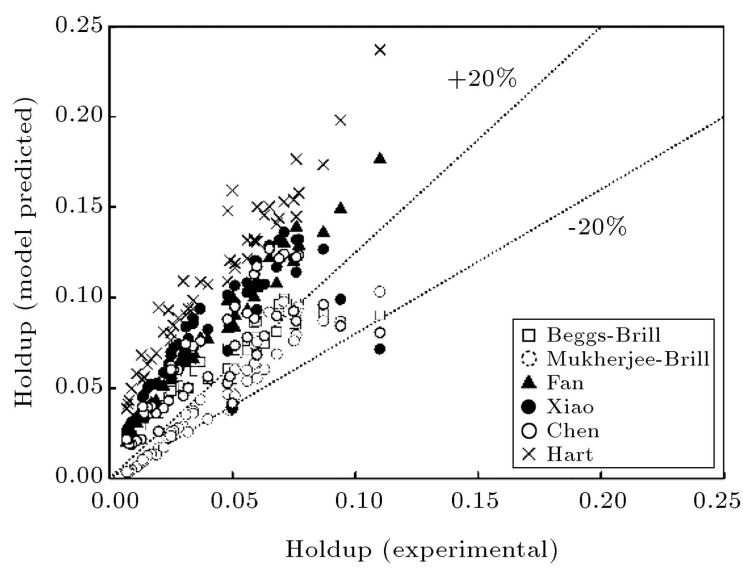

(a)

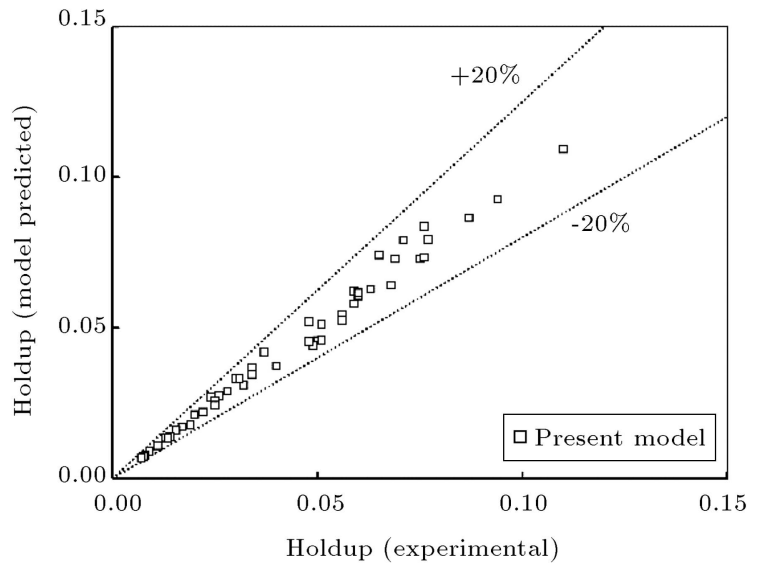

(b)

Figure 10. Comparison of predictions of liquid holdup in different models and experimental values: (a) B-B, M-B, Fan, Xiao, Chen, and Hart models, and (b) the present model.

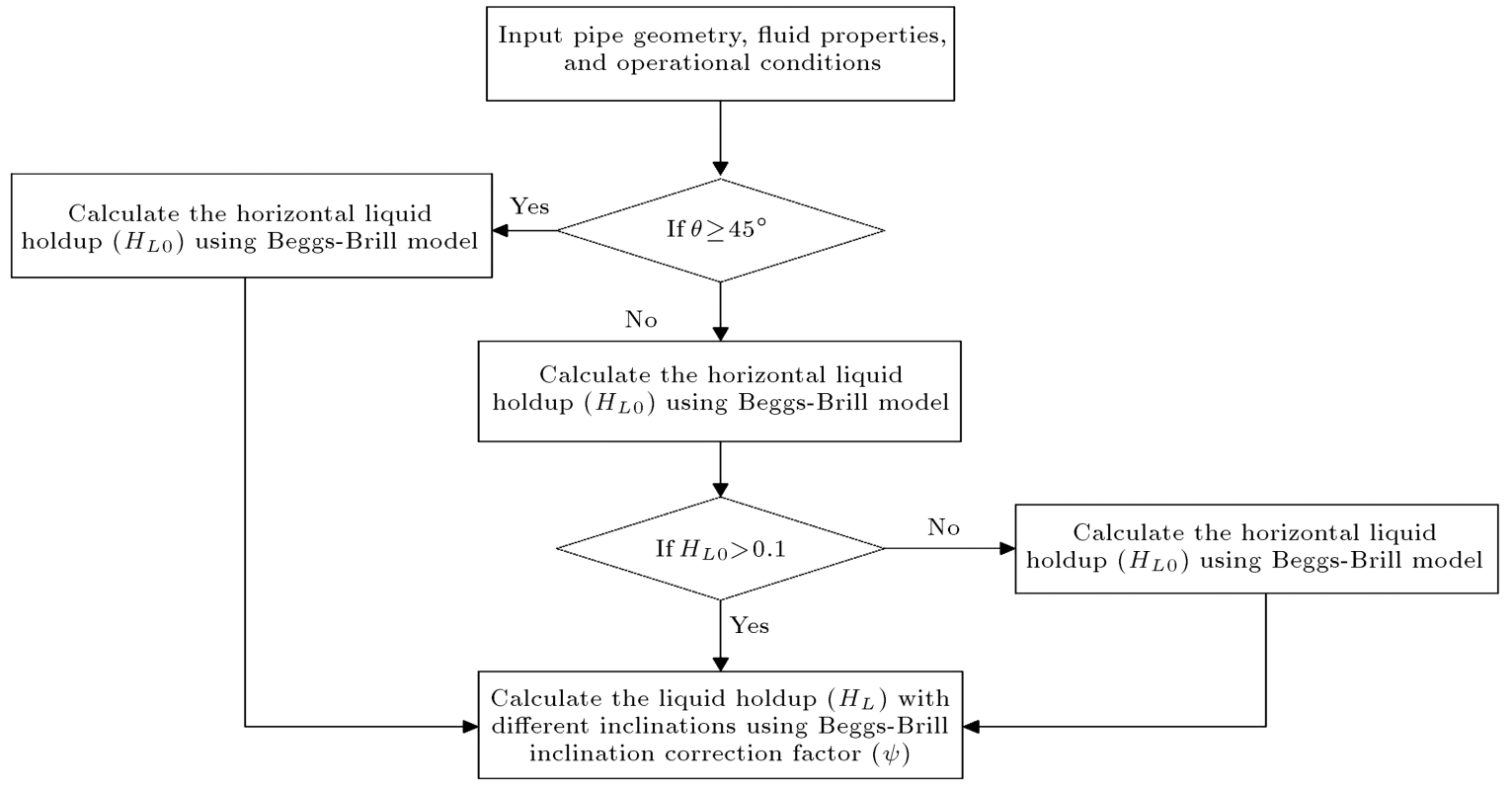

Figure 11. Calculation flow chart for the new model.

Table 5. B-B model errors for different angles.

\begin{tabular}{ccccccccc}
\hline Angle of inclination $\left({ }^{\circ}\right)$ & $\mathbf{0}$ & $\mathbf{1 5}$ & $\mathbf{3 0}$ & $\mathbf{4 5}$ & $\mathbf{6 0}$ & $\mathbf{7 5}$ & $\mathbf{9 0}$ & $\mathbf{0} \sim \mathbf{9 0}$ \\
\hline$E_{1}(\%)$ & -2.2 & -0.7 & -0.5 & -0.4 & -0.8 & -5.5 & -4.5 & -2.0 \\
$E_{2}(\%)$ & 7.2 & 9.3 & 11.2 & 11.6 & 13.3 & 10.0 & 8.7 & 10.0 \\
\hline
\end{tabular}

The average relative error and average absolute error of the new model are shown in Table 5. The table shows that, compared with the B-B model, the error of the new model in $0 \sim 30^{\circ}$ is clearly reduced, and the average absolute error is approximately $10 \%$. Overall, the predicted average relative error and average absolute error of the new model are $2 \%$ and $10 \%$, respectively. In addition, the prediction accuracy is improved compared with those of the B-B model and the Kaya model. The new model is useful for predicting the liquid holdup of gas and liquid at high velocities.

\section{Conclusions}

To obtain an accurate two-fluid model for the prediction of liquid holdup for all inclinations at high gas and liquid velocities, 548 liquid holdup data points were obtained from the multi-phase flow experimental 
laboratory of the Yangtze University from the study. The following conclusions can be reached:

1. Under a certain superficial liquid velocity, the liquid holdup decreased with the increase of superficial gas velocity, while the liquid holdup increased gradually with the increase of superficial liquid velocity. The liquid holdup increased with the increase of the angle and reached the maximum value at the angle of $45^{\circ}$. Then, with the increase of the angle, the liquid holdup changed a little and slightly decreased. With the insignificant increase of gas velocity, the effect of angle on liquid holdup decreased when the inclination of angle was less than $45^{\circ}$.

2. A new two-fluid model for predicting liquid holdup for annular flow in horizontal pipes was presented. Predictions of the model were found to be accurate and in agreement with experimental data. The average absolute error was $4.8 \%$. In addition, a modified B-B model for calculating the liquid holdup at different angles was also presented. The error of the new model was lower, and the average absolute error was $10 \%$. Both models were applicable to high gas and liquid velocities.

\section{Acknowledgments}

The authors are grateful to everyone at the Branch of Key Laboratory of CNPC for Oil and Gas Production and Key Laboratory of Exploration Technologies for Oil and Gas Resources for their assistance. This work was supported by the National Natural Science Found Project (No. 61572084) and National Key Scientific and Technological Project (2016ZX05056004-002, 2017ZX05030-005).

\section{References}

1. Beggs, D.H. and Brill, J.P. "An experimental study of two-phase flow in inclined pipes", Journal of Petroleum Technology, 25(5), pp. 607-617 (1973).

2. Mukherjee, H. and Brill, J.P. "Liquid holdup correlations for inclined two-phase flow", Journal of Petroleum Technology, 35(5), pp. 1003-1008 (1983).

3. Eaton, B.A., Knowles, C.R., and Silberbrg, I.H. "The prediction of flow patterns, liquid holdup and pressure losses occurring during continuous two-phase flow in horizontal pipelines", Journal of Petroleum Technology, 19(6), pp. 815-828 (1967).

4. Barnea, D. "A unified model for predicting flowpattern transitions for the whole range of pipe inclinations", International Journal of Multiphase Flow, 13(1), pp. 1-12 (1987).

5. Xiao, J.J., A Comprehensive Mechanistic Model for Two-Phase Flow in Pipelines, M.S. Thesis, University of Tulsa, Tulsa, OK (1990).
6. Kaya, A.S., Sarica, C., and Brill, J.P. "Mechanistic modeling of two-phase flow in deviated wells", Spe Production and Facilities, 16(3), pp. 156-165 (1999).

7. Gomez, L., Shoham, O., Schmidt, Z., Chokshi, R., Brown, A., and Northug, T., A Unified Mechanistic Model for Steady-State Two-Phase Flow in Wellbores and Pipelines, Ediciones El País (1999).

8. Zhang, H.Q., Wang, Q., Sarica, C., and Brill, J.P. "Unified model for gas-liquid pipe flow via slug dynamics: Part 1 - model development", Journal of Energy Resources Technology, 125(4), pp. 811-820 (2003).

9. Khasanov, M.M., Krasnov, V., Khabibullin, R., Pashali, A., and Guk, V. "A simple mechanistic model for void-fraction and pressure-gradient prediction in vertical and inclined gas/liquid flow", Spe Production \& Operations, 24(1), pp. 165-170 (2009).

10. Saffari, H. and Dalir, N. "Calculation of pressure drop inside condensing vertical pipes in new inlet pressures using a new modified three-fluid model", Scientia Iranica, 20(3), pp. 477-482 (2013).

11. Firouzi, M., Towler, B.F., and Rufford, T.E. "Mechanistic modelling of counter-current slug flows in vertical annuli", SPE Asia Pacific Unconventional Resources Conference and Exhibition, Society of Petroleum Engineers (SPE) (2015).

12. Wang, S., Zhang, H.Q., Sarica, C., and Pereyra, E. "A mechanistic slug-liquid-holdup model for different oil viscosities and pipe-inclination angles", Spe Production \& Operations, 29(4), pp. 329-336 (2014).

13. Al-Safran, E., Kora, C., and Sarica, C. "Prediction of slug liquid holdup in high viscosity liquid and gas twophase flow in horizontal pipes", Journal of Petroleum Science \& Engineering, 133, pp. 566-575 (2015).

14. Hassanlouei, R.N., Firouzfar, H., Kasiri, N., and Khanof, M.H. "A simple mathematical model for slug liquid holdup in horizontal pipes", Scientia Iranica, 19(6), pp. 1653-1660 (2012).

15. Zuber, N. and Findlay, J.A. "Average volumetric concentration in two-phase flow systems", Journal of Heat Transfer, 87(4), p. 453- (1965).

16. Shi, H., Holmes, J.A., Durlofsky, L.J., Aziz, K., Diaz, L., and Alkaya, B. "Drift-flux modeling of two-phase flow in wellbores", Spe Journal, 10(1), pp. 24-33 (2005).

17. Choi, J., Pereyra, E., Sarica, C., Park, C., and Kang, J.M. "An efficient drift-flux closure relationship to estimate liquid holdups of gas-liquid two-phase flow in pipes", Energies, 5(12), pp. 5294-5306 (2012).

18. Adekomaya, O.A. "An improved version of driftflux model for predicting pressure-gradient and voidfraction in vertical and near vertical slug flow", Journal of Petroleum Science and Engineering, 116(2), pp. 103-108 (2014).

19. Bhagwat, S.M. and Ghajar, A.J. "A flow pattern independent drift flux model based void fraction correlation for a wide range of gas-liquid two phase flow", International Journal of Multiphase Flow, 59(2), pp. 186-205 (2014). 
20. Santim, C., Maria, L.D., and Rosa, E.S. "Analysis of transient horizontal slug flow using a simplified drift flux model", IV Journeys in Multiphase Flows (2015).

21. Mao, K. and Hibiki, T. "Drift-flux model for upward two-phase cross-flow in horizontal tube bundles", International Journal of Multiphase Flow, 91, pp. 170183 (2017).

22. Meng, W., Chen, X.T., Kouba, G.E., Cem, S., and Brill, J.P. "Experimental study of low-liquid-loading gas-liquid flow in near-horizontal pipes", Spe Production and Facilities, 16(4), pp. 240-249 (2003).

23. Fan, Y. "An investigation of low liquid loading gasliquid stratified flow in near-horizontal pipes", Ph.D. dissertation, University of Tulsa, Tulsa (2005).

24. Xu, D., Li, X., Li, Y., and Teng, S. "A two-phase flow model to predict liquid holdup and pressure gradient of horizontal well", SPE/IATMI Asia Pacific Oil and Gas Conference and Exhibition (2015).

25. Khaledi, H.A., Smith, I.E., Unander, T.E., and Nossen, J. "Investigation of two-phase flow pattern, liquid holdup and pressure drop in viscous oil-gas flow", International Journal of Multiphase Flow, 67, pp. 37-51 (2014).

26. Unander, T.E., Smith, I.E., and Nossen, J. "Improved holdup and pressure drop prediction for multiphase flow with gas and high viscosity oil", International Conference on Multiphase Production Technology (2013).

27. Dabirian, R., Padsalgikar, A., Mohammadikharkeshi, M., Mohan, R.S., and Shoham, O. "The effects of phase velocities and fluid properties on liquid holdup under gas-liquid stratified flow", Spe Western Regional Meeting (2018).

28. Omebere-Iyari, N.K., Azzopardi, B.J., Lucas, D., Beyer, M., and Prasser, H.M. "The characteristics of gas/liquid flow in large risers at high pressures", International Journal of Multiphase Flow, 34(5), pp. 461-476 (2008).

29. Brennen, C.E., Fundamentals of Multiphase Flow, Cambridge University Press (2009).

30. Aliyu, A.M., Baba, Y.D., Lao, L., Yeung, H., and Kim, K.C. "Interfacial friction in upward annular gasliquid two-phase flow in pipes", Experimental Thermal \& Fluid Science, 84, pp. 90-109 (2017).

31. Mandhane, J.M., Gregory, G.A., and Aziz, K. "A flow pattern map for gas-liquid flow in horizontal pipes", International Journal of Multiphase Flow, 1(4), pp. 537-553 (1974).

32. Taitel, Y. and Dukler, A.E. "A model for predicting flow regime transitions in horizontal and near horizontal gas-liquid flow", Aiche Journal, 22(1), pp. 47-55 (1976).
33. Kaya, A.S., Sarica, C., and Brill, J.P. "Mechanistic modeling of two-phase flow in deviated wells", Spe Production and Facilities, 16(3), pp. 156-165 (1999).

34. Hart, J., Hamersma, P.J., and Fortuin, J.M.H. "Correlations predicting frictional pressure drop and liquid holdup during horizontal gas-liquid pipe flow with a small liquid holdup", International Journal of Multiphase Flow, 15(6), pp. 947-964 (1989).

35. Badie, S., Hale, C.P., Lawrence, C.J., and Hewitt, G.F. "Pressure gradient and holdup in horizontal two-phase gas-liquid flows with low liquid loading", International Journal of Multiphase Flow, 26(9), pp. 1525-1543 (2000).

36. Chen, X.T., Cal, X.D., and Brill, J.P. "Gas-liquid stratified-wavy flow in horizontal pipelines", Journal of Energy Resources Technology, 119(4), pp. 209-216 (1997).

\section{Biographies}

Zilong Liu obtained both his BSc degree (2007-2011) and MSc degree (2013-2016) in Petroleum Engineering College at Yangtze University, China. He is currently pursuing his PhD in Oil and Gas Transportation and Storage at Yangtze University, Wuhan, China. His main research interest is multiphase flow and gas lift.

Ruiquan Liao is a Professor of Petroleum Engineering at Yangtze University, China. He received his $\mathrm{PhD}$ degree (2002) from Huazhong University of Science and Technology, China. He has published over 100 research papers. His research interests include multiphase flow, oil and gas field development, gas lift, and control science and engineering.

Wei Luo is a Lecturer of Petroleum Engineering at Yangtze University, China. He has worked as an engineer in Gas lift Technology Center in PetroChina Tuha Oilfield Company from 2009 to 2012. He received his PhD degree (2012-2015) from Yangtze University, China. He has published over 10 research papers. His research interests include gas lift design method, multiphase flow, and oil well inflow performance.

Joseph Xavier Francisco Ribeiro obtained both his BSc degree (1999-2003) and MSc degrees (2009-2011) in Mechanical Engineering at the Kwame Nkrumah University of Science and Technology, Ghana. He is currently pursuing his PhD in Oil and Gas Transportation and Storage at Yangtze University, China. His main research interest is multiphase flow. 